\title{
Single-Bundle Anterior Cruciate Ligament Reconstruction: Meta-analysis About Anteromedial Versus the Transtibial Technique
}

\author{
PeiWen Sun \\ Logistics University of People's Armed Police Force, Tianjin, 300309, China
}

Keywords: meta-analysis, anterior cruciate ligament, reconstruction, transportal.

\begin{abstract}
To compare the clinical outcomes of single-bundle anterior cruciate ligament (ACL) reconstruction between the anteromedial (AM) and transtibial (TT) techniques. Methods: we include the clinical randomized controlled trials and prospective and retrospective controlled trials using the single-bundle anterior cruciate ligament (ACL) reconstruction with the anteromedial (AM) or transtibial (TT) techniques published up to July 2018, were retrieved from PubMed, Embase databases and Cochrane Library. The relevant articals were assess the methodological quality by the Physiotherapy Evidence Database (PEDro) scale and the methodological index for non-randomized studies (MINORS) csale. Results: (7)RCTs were included, (9) prospective and retrospective controlled trials were include, with a total of (1418) patients. (723) patients and (695) patients in the AM group and the TT group. And better results were found in the AM group, assessing the postoperative functional outcome of the dichotomous negative rate of the Lachman test, pivots test, IKDC grades and the continuous IKDC scores and lysholm scores $(\mathrm{P}<0.05)$. Conclusions: the outcome of the single-bundle anterior cruciate ligament (ACL) reconstruction may lead a contribution that the right now the AM technology may lead a significational better clinical outcome but we still need more research in the future.
\end{abstract}

\section{Background}

Since the arthroscopic-assisted anterior cruciate ligament(ACL) reconstruction come into being. It soon become the standard method and most frequently performed surgical procedures world wide[1] because of the low success rate and result in persistent rotational laxity[2] in traditional methods of anterior cruciate ligament (ACL) reconstruction. As the time pass by the technology have a huge advanced[3] and numbers of the method were defined in this area[4]. In the past-by the transtibial(TT) technique of the femoral tunnel played the most important role in single-bundle ACL reconstruction[5].but several researches and reports shows the TT technique may lead to possible failure due to the nonanatomic in this method[6]. Therefore the surgeons aim their choice to the the anteromedial (AM) technique which the anteromedial portal helps the surgeon get the freedom to replace the graft to the anatomical position . nowadays AM technique is the most common type of anatomical ACL reconstruction and it is now commonly accepted and adopted to ACL reconstrcution[7, 8]。

Since 2010 there are many research[9] have reported the comparison between anteromedial and the transtibial and some of them show that the AM technique may have a superior outcome, last year two meta-analysis[10, 11](up to 2015) get agreement on the results that based on the physical examination and scoring system results the AM technique is superior to the TT technique. But the RCT and the retrospective results in recent year also lead a idea that the two technique have no clinical differences. So in our meta-analysis we include some new research to make a comparison of the clinical outcome between the AM and TT technique in single-bundle ACL reconstruction. 


\section{Methods}

\subsection{Search strategy:}

PubMed, Embase databases and Cochrane Library were searched from 1 January 2010 to 1 July 2018, by two independent investigators. Search strategies were used with the keywords : ("Randomized Controlled Trials" OR trial OR controlled OR Random*) AND (TP OR transportal OR Transtibial OR "TT technique” OR AMP OR Anteromedial) AND ("Reconstructive Surgical Procedures” OR Arthroscopy OR “Joint instability” OR Reconstructions) AND ("intra-articular knee ligament” OR “Anterior Cruciate Ligament” OR ACL)

\subsection{Inclusion criteria and exclusion criteria:}

Inclusion criteria were identified as follows: 1) all adult patients(more than 18 years old) should underwent the arthroscopic-assisted anterior cruciate ligament(ACL) reconstruction (no limitation about the sex or race or nationality) ;2) comparison of clinical outcome between the AM and TT technique in single-bundle ACL reconstruction;3)study type should be RCT or prospective or retrospective controlled trials;4)outcomes should contains the (Lachman test, pivots, IKDC grades, IKDC scores and lysholm scores). Exclusion criteria were identified as follows:1) animal or cadaver studies;2) comparison were not clinical outcome between the AM and TT technique in single-bundle ACL reconstruction;3)do not using the single-bundle ACL reconstruction. (6) subjects with a low level of evidence; (7) laboratory studies.

\subsection{Literature search:}

Two researchers(x and $\mathrm{x}$ )independently included and excluded studies based in the titles, abstracts and the outcomes. At the end of the search, the disagreements were resolved by the discussion between two.

\subsection{Data extraction:}

Before the topic begin we have already design the data-extraction sheet and all the disagreement were solved by the discussion. Author, publication data , number of patients, follow-up period, graft, Operation mode and outcomes of postoperative and preoperative.

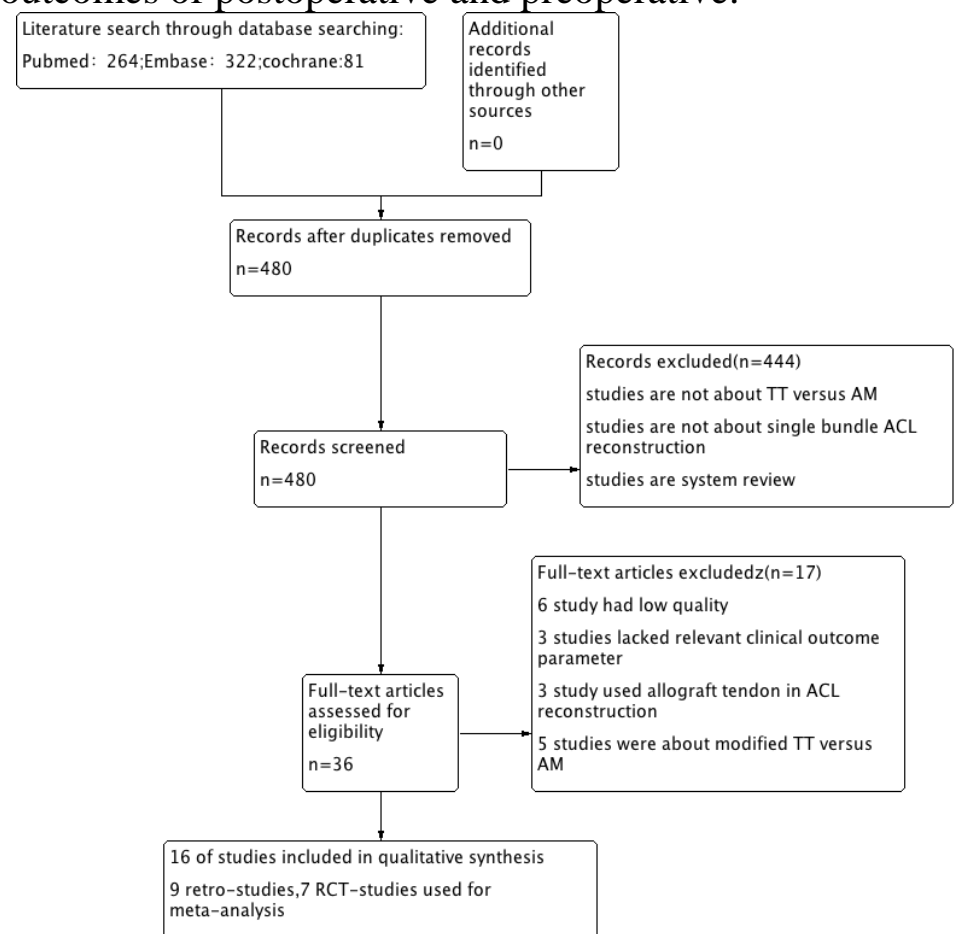

FIG.1 Flowchart of article selection process 


\subsection{Quality assessment:}

The same two researchers independently make the quality assessment by Review manager 5.3 for RCT by the Physiotherapy Evidence Database (PEDro) scale.and use the methodological index for non-randomized studies(MINORS)[12] for prospective and retrospective controlled trials. For the RCT studies, each items get 2 point for low risk 1 point for high risk and 0 point for unclear risk. A trail with score more than 8 was considered to be the high quality study. For the prospective and retrospective controlled trials, 12 items got 2 point for each one and if the study report the item it will get 2 point, if the message is not intact it will get 1 and if the study said nothing then it will be 0.14 point will be a golden line.

\subsection{Statistical analysis:}

We analysed the data using Review Manager 5.3 software. Odds ratio (OR) and $95 \%$ CIs were calculated for dichotomous outcomes. The weighted mean difference (WMD) was calculated with the $95 \%$ CI as a summary statistic for continuous data. The Chi-square test with $\mathrm{N}-1$ degrees of freedom and significance of 0.05 was used to calculate statistical heterogeneity. Inconsistency (I2) was used to calculate the percentage variability in the effect estimates according to heterogeneity: I2 $=((\mathrm{Q}-\mathrm{df}) / \mathrm{Q}) \times 100 \%)$, where $\mathrm{Q}$ is the $\chi 2$ statistic and $\mathrm{df}$ is degrees of freedom. I2 values of 25, 50, and $75 \%$ were considered as low, medium, and high heterogeneity, respectively. The fixed-effects model was used where I $<50 \%$; otherwise, the random-effects model was used. The Grading of Recommendations Assessment, Development, and Evaluation (GRADE)[13] approach was applied to each analysis performed to determine the quality of the evidence

\section{Results}

\subsection{Description of included studies:}

586 articles were found in our research. 187 were exclude after duplication management by using endnote X8. 366 were exclude after reviewed work by tittle and the abstract. 17 were exclude after reviewed work by full test as 6 study had low quality, 3 studies lacked relevant clinical outcome parameter, 3 study used allograft tendon in ACL reconstruction, and 5 studies were about modified TT versus AM. Finally, 16 articles were include in our meta-analysis. A summay is presented in Tab.1.

Tab.1 search result characteristic

\begin{tabular}{|c|c|c|c|c|}
\hline Reference & Publication year & Study design & Sample size & Age of the patients \\
\hline Bohn ${ }^{[14]}$ & 2015 & RCT & $\begin{array}{l}\mathrm{AM}=12 \\
\mathrm{TT}=11\end{array}$ & $\begin{array}{c}\text { AM:24.3/4.9 } \\
\text { TT:27.5/7.2 }\end{array}$ \\
\hline Guglielmetti $^{[15]}$ & 2014 & RCT & $\begin{array}{l}\mathrm{AM}=38 \\
\mathrm{TT}=35\end{array}$ & $<40$ \\
\hline Hussein $^{[16]}$ & 2012 & RCT & $\begin{aligned} \mathrm{AM} & =78 \\
\mathrm{TT} & =72\end{aligned}$ & $\begin{array}{c}\text { AM:34.2 } \\
\text { TT:32.6 }\end{array}$ \\
\hline Mirzatolooei $^{[5]}$ & 2012 & RCT & $\begin{aligned} \mathrm{AM} & =80 \\
\mathrm{TT} & =88\end{aligned}$ & $\begin{array}{c}\text { AM:26.6 } \\
\text { TT:26.8 }\end{array}$ \\
\hline $\operatorname{Noh}^{[17]}$ & 2013 & RCT & $\begin{aligned} \mathrm{AM} & =31 \\
\mathrm{TT} & =30\end{aligned}$ & $\begin{array}{l}\text { AM:22 } \\
\text { TT:24 }\end{array}$ \\
\hline Zhang $^{[18]}$ & 2012 & RCT & $\begin{aligned} \mathrm{AM} & =31 \\
\mathrm{TT} & =34\end{aligned}$ & $>28$ \\
\hline MacDonald $^{[19]}$ & 2017 & RCT & $\begin{aligned} \mathrm{AM} & =46 \\
\mathrm{TT} & =42\end{aligned}$ & $\begin{array}{c}\text { AM:30.7/9.3 } \\
\text { TT:32.4/8.9 }\end{array}$ \\
\hline Alentorn-Geli ${ }^{[20]}$ & 2010 & $\begin{array}{c}\text { Retrospective } \\
\text { nonRCT }\end{array}$ & $\begin{array}{l}\mathrm{AM}=26 \\
\mathrm{TT}=21\end{array}$ & $\begin{array}{c}\text { AM:26.4 } \\
\text { TT:27.5 }\end{array}$ \\
\hline $\operatorname{Kim}^{[21]}$ & 2011 & $\begin{array}{c}\text { Retrospective } \\
\text { nonRCT }\end{array}$ & $\begin{aligned} \mathrm{AM} & =33 \\
\mathrm{TT} & =33\end{aligned}$ & $\begin{array}{c}\text { AM:29.8 } \\
\text { TT:30.3 }\end{array}$ \\
\hline Mardani-Kivi $^{[22]}$ & 2012 & $\begin{array}{l}\text { Retrospective } \\
\text { nonRCT }\end{array}$ & $\begin{aligned} \mathrm{AM} & =64 \\
\mathrm{TT} & =60\end{aligned}$ & 28.5 \\
\hline Franceschi $^{[23]}$ & 2013 & Retrospective & $\mathrm{AM}=42$ & AM:28 \\
\hline
\end{tabular}




\begin{tabular}{|c|c|c|c|c|}
\hline & & nonRCT & $\mathrm{TT}=46$ & TT:29 \\
\hline Azboy $^{[24]}$ & 2014 & $\begin{array}{l}\text { Retrospective } \\
\text { nonRCT }\end{array}$ & $\begin{aligned} \mathrm{AM} & =30 \\
\mathrm{TT} & =34\end{aligned}$ & $\begin{array}{c}\text { AM:26.5 } \\
\text { TT:27.6 }\end{array}$ \\
\hline Sukur $^{[25]}$ & 2016 & $\begin{array}{l}\text { Retrospective } \\
\text { nonRCT }\end{array}$ & $\begin{array}{l}\mathrm{AM}=56 \\
\mathrm{TT}=49\end{array}$ & $\begin{array}{c}\text { AM:25.5 } \\
\text { TT:26.8 }\end{array}$ \\
\hline TaŞdemİ ${ }^{[26]}$ & 2015 & $\begin{array}{l}\text { Retrospective } \\
\text { nonRCT }\end{array}$ & $\begin{array}{c}\mathrm{AM}=24 \\
\mathrm{TT}=15\end{array}$ & $\begin{array}{c}\text { AM:29.04/7.53 } \\
\text { TT:29.73/6.33 }\end{array}$ \\
\hline Zehir ${ }^{[27]}$ & 2015 & $\begin{array}{l}\text { Retrospective } \\
\text { nonRCT }\end{array}$ & $\begin{array}{l}\mathrm{AM}=71 \\
\mathrm{TT}=58\end{array}$ & \\
\hline Mulcahey $^{[28]}$ & 2014 & $\begin{array}{c}\text { Retrospective } \\
\text { nonRCT }\end{array}$ & $\begin{aligned} \mathrm{AM} & =61 \\
\mathrm{TT} & =67\end{aligned}$ & \\
\hline
\end{tabular}

\subsection{Quality of the evidence}

The 7 articles we included in our research involved in 7 RCT and 9 retrospective study.so the quality of the evidence in our study is enough that high. The result have a agreement on the comparison between two techinology. Besides, we compare the results of the meta-analysis results before and get agreement PEDro critical appraisal tool results

\begin{tabular}{|c|c|c|c|c|c|c|c|}
\hline & $\begin{array}{l}\text { Bohn } \\
2015\end{array}$ & $\begin{array}{l}\text { Guglielmetti } \\
2014\end{array}$ & $\begin{array}{c}\text { Hussein } \\
2012\end{array}$ & $\begin{array}{l}\text { Mirzatolooei } \\
2012\end{array}$ & $\begin{array}{c}\text { Zhang } \\
2012\end{array}$ & $\begin{array}{l}\text { Noh } \\
2013\end{array}$ & $\begin{array}{l}\text { MacDonald } \\
2017\end{array}$ \\
\hline Eligibility criteria were specified & $\mathrm{Y}$ & $\mathrm{Y}$ & $\mathrm{Y}$ & $\mathrm{Y}$ & $\mathrm{Y}$ & $\mathrm{Y}$ & $\mathrm{Y}$ \\
\hline $\begin{array}{l}\text { Randomized } \\
\text { adequatel }\end{array}$ & $\mathrm{Y}$ & $\mathrm{Y}$ & $\mathrm{Y}$ & $\mathrm{Y}$ & $\mathrm{Y}$ & $\mathrm{Y}$ & $\mathrm{Y}$ \\
\hline allocation was concealed & $\mathrm{Y}$ & $\mathrm{Y}$ & $\mathrm{N}$ & $\mathrm{N}$ & $\mathrm{N}$ & $\mathrm{N}$ & $\mathrm{Y}$ \\
\hline similar at baseline & $\mathrm{Y}$ & Y & $\mathrm{Y}$ & $\mathrm{Y}$ & $\mathrm{Y}$ & $\mathrm{Y}$ & $\mathrm{Y}$ \\
\hline Procedure blinded & Y & $\mathrm{N}$ & $\mathrm{N}$ & $\mathrm{N}$ & $\mathrm{Y}$ & $\mathrm{N}$ & Y \\
\hline therapy were blinded; & $\mathrm{N}$ & $\mathrm{N}$ & $\mathrm{N}$ & $\mathrm{N}$ & $\mathrm{N}$ & $\mathrm{N}$ & $\mathrm{N}$ \\
\hline Outcome Assessor blinded & $\mathrm{Y}$ & $\mathrm{N}$ & $\mathrm{Y}$ & $\mathrm{Y}$ & $\mathrm{N}$ & $\mathrm{Y}$ & $\mathrm{Y}$ \\
\hline $\begin{array}{c}\text { at least one key outcome were } \\
\text { obtained from } \geq 85 \% \text { of the } \\
\text { subjects }\end{array}$ & $\mathrm{Y}$ & $\mathrm{Y}$ & $\mathrm{Y}$ & $\mathrm{Y}$ & $\mathrm{Y}$ & $\mathrm{Y}$ & $\mathrm{Y}$ \\
\hline $\begin{array}{l}\text { at least one key outcome was } \\
\text { analyzed by intention to treat }\end{array}$ & $\mathrm{Y}$ & $\mathrm{Y}$ & $\mathrm{Y}$ & $\mathrm{Y}$ & $\mathrm{Y}$ & $\mathrm{Y}$ & $\mathrm{Y}$ \\
\hline reported at least one key outcome & Y & Y & Y & Y & $\mathrm{Y}$ & $\mathrm{Y}$ & $\mathrm{Y}$ \\
\hline $\begin{array}{l}\text { provides both point measures and } \\
\text { measures of variability }\end{array}$ & $\mathrm{Y}$ & $\mathrm{Y}$ & $\mathrm{Y}$ & $\mathrm{Y}$ & $\mathrm{Y}$ & $\mathrm{Y}$ & $\mathrm{Y}$ \\
\hline
\end{tabular}

\subsection{Characteristics and interventions:}

All 16 research selected articles were written in English and compare the clinical outcome. Of the $\mathrm{n}$ studies included in the this artical, all of them reported outcomes of anteromedial technology versus transtibial. These 16 studies included a total of 1418 patients, of whom 723 (51\%) underwent the anteromedial technique and 695 (49\%) underwent the transtibial for knee arthroscopy.

11 studies that were reviewed for Lachman test findings, involving a total of 848 patients, were productive studies. The overall Odds Ratio $(\mathrm{OR})=0.43,95 \%$ CI $(0.31,0.59), \mathrm{P}<0.00001$.). 


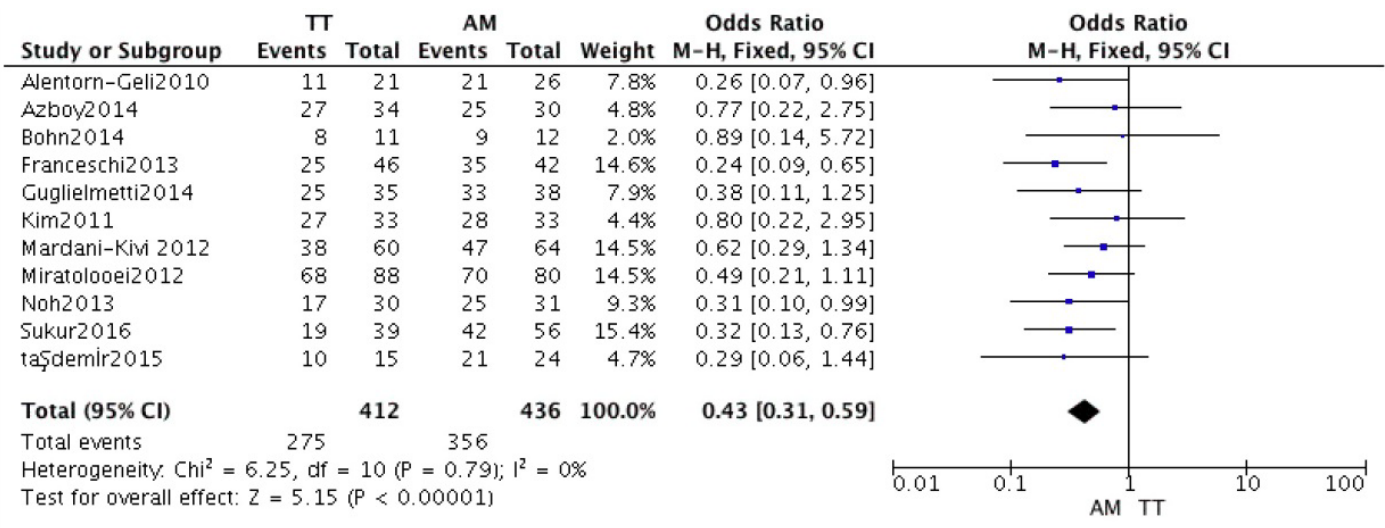

Caption

Forest plot of comparison: 1 anteromeidal vs transtibial, outcome: 1.2 lachman.

13 study and 1037 patients were reviewed for pivots findings. The overall OR $=0.3595 \% \mathrm{CI}(0.26$, 0.47),P $<0.00001)$. They were significantly different from each other in two modus operandi.

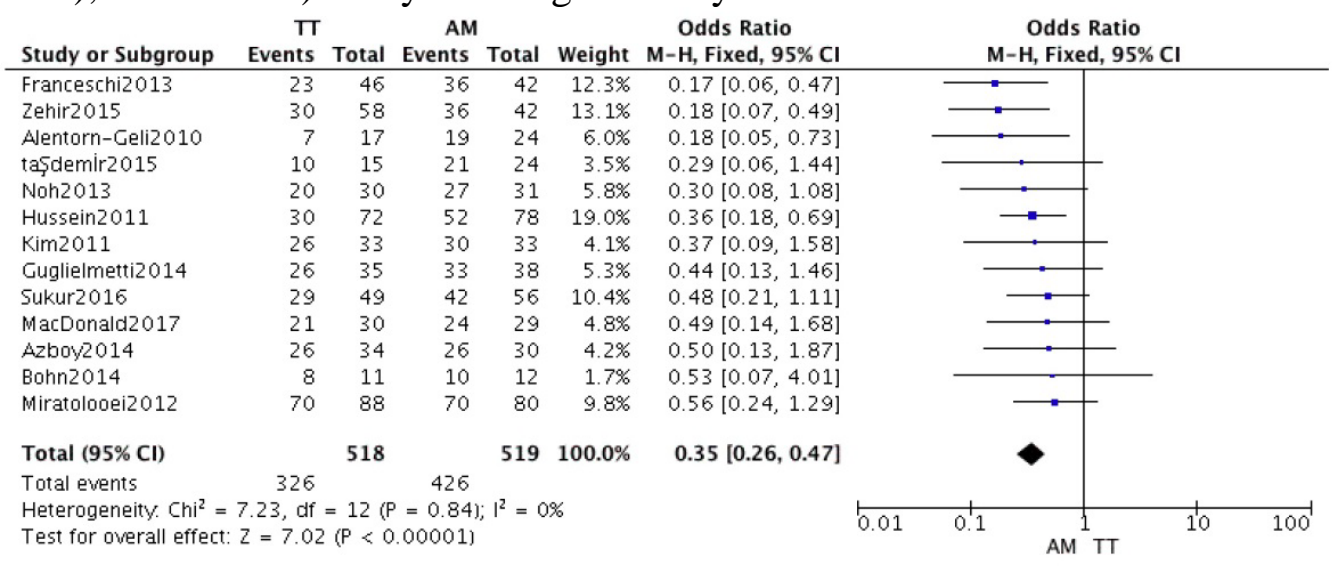

Caption

Forest plot of comparison: 1 anteromeidal vs transtibial, outcome: 1.1 pivots.

\section{Discussion}

In our meta-analysis we compare the two different modus operandi about the anteromedial and transtibial in single bundle autologous ACL reconstruction. We included 16 article in our meta analysis and 7 of them is RCT, involving a total of 1418 patients. and choice IKDC grades, lachman test pivots test IKDC scores and lysholm scores as the index in the comparison between anteromedial Versus transtibial. The most important finding in our present research was that all of the results showed the obvious clinical different. This may lead an idea that there may be a choice between that two but the reason of the choice in modus operandi may based on the clinical outcome about the stability of the sagittal and the rotational.

The limitations in our meta-analysis were acknowledged that:1)the retrospective studies lacked of the randomization and the bliding. But we extracted the low qualities studies and only included the researches since 2010 to low the influence of the qualities of the study.

\section{Conclusion}

As we include 16 article to make a meta-analysis. the main finding of this analysis that we have is that: 1)although the AM group shows a better outcome but the time part paly a unknown role in the comparision. 2)we may think that the numbers of the whole sample size in the research is not that enough.3)we may think that the feminine gender didn't get the enough chance to show their report,4)the time of the follow-up period is not that long to make a deep comparision. 


\section{References}

[1] Kopf, S., et al., Nonanatomic tunnel position in traditional transtibial single-bundle anterior cruciate ligament reconstruction evaluated by three-dimensional computed tomography. J Bone Joint Surg Am, 2010. 92(6): p. 1427-31.

[2] Ristanis, S., et al., The effects of anterior cruciate ligament reconstruction on tibial rotation during pivoting after descending stairs. Knee Surg Sports Traumatol Arthrosc, 2003. 11(6): p. 360-5.

[3] Csintalan, R.P., M.C. Inacio, and T.T. Funahashi, Incidence rate of anterior cruciate ligament reconstructions. Perm J, 2008. 12(3): p. 17-21.

[4] Silva, A., R. Sampaio, and E. Pinto, ACL reconstruction: comparison between transtibial and anteromedial portal techniques. Knee Surg Sports Traumatol Arthrosc, 2012. 20(5): p. 896-903.

[5] Mirzatolooei, F., Comparison of short term clinical outcomes between transtibial and transportal TransFix(R) femoral fixation in hamstring ACL reconstruction. Acta Orthop Traumatol Turc, 2012. 46(5): p. 361-6.

[6] Strauss, E.J., et al., Can Anatomic Femoral Tunnel Placement Be Achieved Using a Transtibial Technique for Hamstring Anterior Cruciate Ligament Reconstruction? American Journal of Sports Medicine, 2011. 39(6): p. 1263-1269.

[7] Bottoni, C.R., Anterior Cruciate Ligament Femoral Tunnel Creation by Use of Anteromedial Portal. Arthroscopy-the Journal of Arthroscopic and Related Surgery, 2008. 24(11): p. 1319-1319.

[8] Harner, C.D., N.J. Honkamp, and A.S. Ranawat, Anteromedial portal technique for creating the anterior cruciate ligament femoral tunnel. Arthroscopy-the Journal of Arthroscopic and Related Surgery, 2008. 24(1): p. 113-115.

[9] Chen, Y.S., et al., Outcome of Single-Bundle Hamstring Anterior Cruciate Ligament Reconstruction Using the Anteromedial Versus the Transtibial Technique: A Systematic Review and Meta-analysis. Arthroscopy-the Journal of Arthroscopic and Related Surgery, 2015. 31(9): p. 1784-1794.

[10] Chen, H.T., et al., Anteromedial versus transtibial technique in single-bundle autologous hamstring ACL reconstruction: a meta-analysis of prospective randomized controlled trials. Journal of Orthopaedic Surgery and Research, 2017. 12.

[11] Liu, A., et al., Clinical outcomes of transtibial versus anteromedial drilling techniques to prepare the femoral tunnel during anterior cruciate ligament reconstruction. Knee Surgery Sports Traumatology Arthroscopy, 2017. 25(9): p. 2751-2759.

[12] Slim, K., et al., Methodological index for non-randomized studies (minors): development and validation of a new instrument. ANZ J Surg, 2003. 73(9): p. 712-6.

[13] Brozek, J.L., et al., Grading quality of evidence and strength of recommendations in clinical practice guidelines part 3 of 3. The GRADE approach to developing recommendations. Allergy, 2011. 66(5): p. 588-95.

[14] Bohn, M.B., et al., Rotational laxity after anatomical ACL reconstruction measured by 3-D motion analysis: a prospective randomized clinical trial comparing anatomic and nonanatomic ACL reconstruction techniques. Knee Surg Sports Traumatol Arthrosc, 2015. 23(12): p. 3473-81.

[15] Guglielmetti, L.G., et al., Anterior cruciate ligament reconstruction: a new cortical suspension device for femoral fixation with transtibial and transportal techniques. J Orthop Surg Res, 2014. 9: p. 110. 
[16] Hussein, M., et al., Prospective randomized clinical evaluation of conventional single-bundle, anatomic single-bundle, and anatomic double-bundle anterior cruciate ligament reconstruction: 281 cases with 3- to 5-year follow-up. Am J Sports Med, 2012. 40(3): p. 512-20.

[17] Noh, J.H., et al., Femoral tunnel position on conventional magnetic resonance imaging after anterior cruciate ligament reconstruction in young men: transtibial technique versus anteromedial portal technique. Arthroscopy, 2013. 29(5): p. 882-90.

[18] Zhang, Q., et al., Comparison of two methods of femoral tunnel preparation in single-bundle anterior cruciate ligament reconstruction: a prospective randomized study. Acta Cir Bras, 2012. 27(8): p. 572-6. 